University of Nebraska - Lincoln

DigitalCommons@University of Nebraska - Lincoln

Faculty Publications, Department of Mathematics

Mathematics, Department of

$12-1964$

\title{
MODULES OVER COMMUTATIVE RINGS
}

William G. Leavitt

University of Nebraska - Lincoln

Follow this and additional works at: https://digitalcommons.unl.edu/mathfacpub

Part of the Mathematics Commons

Leavitt, William G., "MODULES OVER COMMUTATIVE RINGS" (1964). Faculty Publications, Department of Mathematics. 47.

https://digitalcommons.unl.edu/mathfacpub/47

This Article is brought to you for free and open access by the Mathematics, Department of at DigitalCommons@University of Nebraska - Lincoln. It has been accepted for inclusion in Faculty Publications, Department of Mathematics by an authorized administrator of DigitalCommons@University of Nebraska - Lincoln. 


\title{
CLASSROOM NOTES
}

\author{
Edited by Gertrude EhrLich, University of Maryland
}

This department welcomes brief expository articles on problems and topics closely related to classroom experience in courses that are normally available to undergraduate students, from the freshman year through early graduate work. Items of interest to teachers, such as pedagogical tactics, course improvement, new proofs and counterexamples, and fresh viewpoints in general, are invited. All material should be sent to Gertrude Ehrlich, Mathematics Department, University of Maryland, College Park, Maryland 20740.

\section{MODULES OVER COMMUTATIVE RINGS}

W. G. LEAvitT, University of Nebraska

The following is another short proof of the fact that for a commutative ring with unit $R$, any finitely based $R$-module is "dimensional" in the sense that all of its bases have the same number of elements.

Theorem. Let $R$ be a commutative ring with unit. If $M$ is a unitary $R$-module with a basis of $n$ elements, then all bases of $M$ contain exactly $n$ elements.

Proof. (The method is that of [1], p. 115.) Let $\left\{\alpha_{i}\right\}(i=1, \cdots, n)$ be a basis for $M$. It is easy to see that $M$ cannot have an infinite basis. (See [2], p. 241-2. Applied to modules, the method shows that for a module with an infinite basis all bases have the same cardinality.) Thus let $\left\{\beta_{j}\right\}(j=1, \cdots, m)$ be another 
basis of $M$. Write $\alpha_{i}=\sum_{j=1}^{m} a_{i j} \beta_{j}(i=1, \cdots, n)$ and $\beta_{j}=\sum_{k=1}^{n} b_{j k} \alpha_{k}$ $(j=1, \cdots, m)$. If $A=\left[a_{i j}\right]$ and $B=\left[b_{i j}\right]$, it follows from the independence of the $\alpha_{i}$ 's and the $\beta_{j}$ 's that

$$
\text { (1) } A B=I_{n} \text { and (2) } B A=I_{m} \text {, }
$$

where $I_{n}$ and $I_{m}$ are unit matrices. Conversely, the existence of relations (1) and (2) in a ring $R$ implies the existence of an $R$-module with bases of lengths $m$ and $n$, namely the module of all $m$-tuples. This module has, of course, the rows of $I_{m}$ as a basis, but also has as an alternative basis the rows of $A$. This is clear, since from (2) each row of $I_{m}$ is a linear combination of the rows of $A$, while from (1), $X A=0$ implies $X I_{n}=X=0$, so the rows of $A$ are independent.

Now any homomorphism of $R$ preserves the relations (1) and (2), and so any nonzero homomorphic image of $R$ also admits a module with bases of lengths $m$ and $n$. But if we apply Zorn's lemma in the usual way (relative to ideals not containing the unit, partially ordered by set inclusion) we obtain a maximal ideal $I$ of $R$. Since $R / I$ is a field, its modules are vector spaces all of whose bases are of the same length. Thus since $R / I$ is a homomorphic image of $R$, we must conclude that $m=n$.

\section{References}

1. W. G. Leavitt, The module type of a ring, Trans. Am. Math. Soc., 103 (1962) 113-130.

2. N. Jacobson, Lectures in abstract algebra, vol. II, Van Nostrand, New York, 1953. 